\title{
Pharmacokinetics and Tolerability of Multiple Doses of Pharmaceutical-Grade Synthetic Cannabidiol in Pediatric Patients with Treatment-Resistant Epilepsy
}

\author{
James W. Wheless ${ }^{1}$. Dennis Dlugos ${ }^{2} \cdot$ Ian Miller ${ }^{3} \cdot$ D. Alexander $\mathrm{Oh}^{4,11} \cdot$ Neha Parikh $^{4}$. Steven Phillips ${ }^{5}$. \\ J. Ben Renfroe ${ }^{6}$. Colin M. Roberts ${ }^{7}$. Isra Saeed ${ }^{8} \cdot$ Steven P. Sparagana ${ }^{9} \cdot$ Jin $\mathrm{Yu}^{4} \cdot$ Maria Roberta Cilio $^{8,10}$ (1) on behalf \\ of the INS011-14-029 Study Investigators
}

Published online: 2 May 2019

(c) The Author(s) 2019

\begin{abstract}
Background Prior studies have evaluated the use of various constituents of cannabis for their anti-seizure effects. Specifically, cannabidiol, a non-psychoactive component of cannabis, has been investigated for treatment-resistant epilepsy, but more information is needed particularly on its use in a pediatric population.

Objective The objective of this study was to evaluate the pharmacokinetics and safety of a synthetic pharmaceutical-grade cannabidiol oral solution in pediatric patients with treatment-resistant epilepsy.

Methods In this open-label study, pediatric patients (aged 1 to $\leq 17$ years) with treatment-resistant epilepsy received cannabidiol oral solution administered as add-on to their current antiepileptic drug regimen. Patients received a single dose $(5,10$, or $20 \mathrm{mg} / \mathrm{kg})$ on day 1 and twice-daily dosing on days 4 through 10 (10-mg/kg [cohort 1], 20-mg/kg [cohort 2], or 40-mg/kg [cohort 3] total daily dose). Serial blood samples were collected on day 1 before dosing and up to $72 \mathrm{~h}$ post-dose, and on day 10 before dosing and up to $24 \mathrm{~h}$ post-dose. Blood samples to assess trough concentrations of cannabidiol were collected on day 6 (for patients aged 12 to $\leq 17$ years), day 8 (for patients aged 2 to $\leq 17$ years), and day 9 (for patients aged 6 to $\leq 17$ years).

Results Overall, 61 patients across three cohorts received one of three doses of cannabidiol oral solution (mean age, 7.6 years). The age composition was similar in the three cohorts. There was a trend for increased cannabidiol exposure with increased cannabidiol oral solution dosing, but overall exposure varied. Approximately 2-6 days of twice-daily dosing provided steady-state concentrations of cannabidiol. A bi-directional drug interaction occurred with cannabidiol and clobazam. Concomitant administration of clobazam with $40 \mathrm{mg} / \mathrm{kg}$ /day of cannabidiol oral solution resulted in a 2.5 -fold increase in mean cannabidiol exposure. Mean plasma clobazam concentrations were 1.7- and 2.2-fold greater in patients receiving clobazam concomitantly with $40 \mathrm{mg} / \mathrm{kg} /$ day of cannabidiol oral solution compared with $10 \mathrm{mg} / \mathrm{kg} / \mathrm{day}$ and $20 \mathrm{mg} /$ $\mathrm{kg} /$ day. Mean plasma norclobazam values were 1.3- and 1.9-fold higher for patients taking clobazam plus $40 \mathrm{mg} / \mathrm{kg} / \mathrm{day}$ of cannabidiol oral solution compared with the $10-\mathrm{mg} / \mathrm{kg} / \mathrm{day}$ and $20-\mathrm{mg} / \mathrm{kg} /$ day groups. All doses were generally well tolerated, and common adverse events that occurred at $>10 \%$ were somnolence $(21.3 \%)$, anemia $(18.0 \%)$, and diarrhea $(16.4 \%)$. Conclusions Inter-individual variability in systemic cannabidiol exposure after pediatric patient treatment with cannabidiol oral solution was observed but decreased with multiple doses. Short-term administration was generally safe and well tolerated. Trial Registration ClinicalTrials.gov (NCT02324673).
\end{abstract}

\section{Introduction}

Electronic supplementary material The online version of this article (https://doi.org/10.1007/s40263-019-00624-4) contains supplementary material, which is available to authorized users.

Maria Roberta Cilio

Roberta.Cilio@ucsf.edu

Extended author information available on the last page of the article
In the USA, the prevalence of epilepsy and seizure disorders in children has been estimated at $1 \%$ [1]. Currently, several non-pharmacologic interventions, such as resective surgery, dietary intervention (e.g., ketogenic diet), neurostimulation (e.g., vagus nerve stimulation or responsive neurostimulation), and pharmacologic therapies, are used 


\section{Key Points}

Data on the pharmacokinetics of cannabidiol in pediatric patients are lacking, and the proper dose for titration and optimization of safety is unclear.

Pharmaceutical-grade synthetic cannabidiol oral solution was generally safe and well tolerated; common adverse events were somnolence, anemia, and diarrhea. The study showed that systemic cannabidiol exposure generally increased linearly with increases in dose.

Close monitoring of plasma concentrations of antiepileptic drugs and their clinical effects may be needed in pediatric patients receiving clobazam concomitantly with cannabidiol, particularly at higher doses, as drug-drug interactions have been observed with increased exposure to cannabidiol, clobazam, and norclobazam.

to treat children with epilepsy [2, 3]. Despite the availability of several treatment options, a prospective observational study of 470 previously untreated children, adolescents, and adults with epilepsy showed that only $47 \%$ of patients had a response to initial monotherapy and only an additional $13 \%$ responded to a second monotherapy [4]. Of the 70 patients who received combination therapy, only $23 \%$ of patients who received two drugs were seizure free; further, no patients who received three drugs were free of seizures [4]. Therefore, there remains an unmet need for novel treatments.

Cannabidiol is a novel compound with central nervous system activity and, unlike other cannabinoids (e.g., tetrahydrocannabinol), produces no euphoria. Cannabidiol has a low affinity for the endogenous cannabinoid receptors and may modulate neuronal hyperexcitability through other mechanisms [5]. The possible mechanisms of anticonvulsive action include an anti-inflammatory effect on the nervous system, inverse agonism (or antagonism) at the cannabinoid receptors, modulation of neuronal channels, and enhancement of anandamide action [6-11]. Given these attributes, cannabidiol is being evaluated as a potential therapeutic option for several disorders, including seizures, chemotherapy-induced nausea and vomiting, spasticity, tics, posttraumatic stress disorder, and neuropathic pain, with seizures being, by far, the most frequently investigated condition [12, 13]. Indeed, previous studies have shown potential benefit of pure cannabidiol in decreasing the number of seizures in patients with treatment-resistant epilepsy associated with different forms of epilepsy, including Dravet syndrome and Lennox-Gastaut syndrome [14-19].

A highly purified plant-based form of oral cannabidiol formulation was approved by the US Food and Drug Administration in 2018 for the treatment of Dravet and
Lennox-Gastaut syndromes in patients aged $\geq 2$ years [20]. Two randomized, phase III clinical trials in children, adolescents, and adults with Lennox-Gastaut syndrome demonstrated that plant-based cannabidiol decreased the monthly frequency of seizures [17, 19]. A clinical trial on the safety and pharmacokinetic (PK) parameters of cannabidiol (5to $20-\mathrm{mg} / \mathrm{kg} /$ day doses) for the treatment of seizures in 34 children (aged 4-10 years) with Dravet syndrome reported common adverse events (AEs) of pyrexia, somnolence, decreased appetite, sedation, vomiting, ataxia, and abnormal behavior in three or more patients at all doses tested [21]. Additional open-label studies have shown that cannabidiol was efficacious in decreasing median monthly seizure frequency in treatment-resistant epilepsies of multiple etiologies $[18,22]$.

Currently, there are still limited published data on the PK parameters and drug interactions related to cannabidiol use in the pediatric epilepsy population. The objective of this study was to characterize the PK parameters and short-term tolerability of pharmaceutical-grade synthetic cannabidiol oral solution in pediatric patients with treatment-resistant epilepsy. The current study is the first to examine the synthetic cannabidiol formulation in humans.

\section{Methods}

\subsection{Patient Population}

Individuals aged 1-17 years who weighed between $\geq 9$ and $\leq 90 \mathrm{~kg}$ and had treatment-resistant epilepsy were eligible for inclusion. Epilepsy was considered "treatment resistant" if patients had recurrent seizures despite adequate trials of three or more antiepileptic drugs and one or more prior adequate treatment courses with two or more antiepileptic drugs in combination. Patients were required to have been on a stable-dose antiepileptic drug regimen for $\geq 30$ days prior to day 0 and to remain on that regimen for the entire duration of the study. Vagus nerve stimulation and adherence to a ketogenic diet were not counted as part of the antiepileptic drug regimen in this trial. However, the settings for vagus nerve stimulator treatment had to remain stable during the study. Similarly, for individuals on a ketogenic diet, the fat-to-carbohydrate ratio and daily protein intake needed to remain stable during the study. Additional inclusion criteria were use of contraception by both male and female individuals of childbearing age, lack of pregnancy in female individuals, willingness to comply with study procedures, and general good health, as determined by the investigator. Patients were excluded if they had any clinically significant abnormality, suicidal ideation or history of attempted suicide, history of allergic reaction to study drug, or known infection with hepatitis $\mathrm{B}$ or $\mathrm{C}$ or human immunodeficiency 
virus. The initiation of felbamate $<6$ months before the screening visit and the use of any cannabinoids (e.g., cannabidiol, hemp oil, marijuana) in the 30 days before screening were not permitted. Patients with electrocardiogram results that were considered clinically significant by the investigator at time of enrollment, or a history of such results, were excluded.

Because cannabidiol inhibits or is a substrate for some members of the cytochrome P450 (CYP) protein family, particularly CYP2C19, and others such as CYP3A4, CYP3A5, and CYP3A7 [11, 23, 24], patients who received CYP inhibitors, inducers, or sensitive substrates with a narrow therapeutic index (Electronic Supplementary Material) were excluded from participation, as were patients with any disorder or history of a condition (e.g., malabsorption) that could have interfered with drug absorption, distribution, metabolism, or excretion. Patients were asked to refrain from consuming grapefruit, Seville oranges, and products made from these fruits (e.g., grapefruit juice, Seville orange marmalade).

\subsection{Study Design}

This open-label, multiple-ascending dose, phase I/II study consisted of an up to 28-day screening phase, a 10-day treatment phase, and a 7-day follow-up period (Fig. 1). Patients who completed the study could be enrolled in an open-label extension study; data from that study will be published in a follow-on manuscript. Patients were randomly assigned to one of three cohorts: cannabidiol oral solution of $10 \mathrm{mg} /$ $\mathrm{kg} /$ day $(80 \mathrm{mg} / \mathrm{mL}$; cohort 1$), 20 \mathrm{mg} / \mathrm{kg} /$ day $(300 \mathrm{mg} / \mathrm{mL}$; cohort 2), or $40 \mathrm{mg} / \mathrm{kg} / \mathrm{day}$ ( $300 \mathrm{mg} / \mathrm{mL}$; cohort 3). These total daily doses were selected based on the tolerability and safety profiles reported for various cannabidiol product concentrations [25] and the anticipated body weight range of participants. The active ingredient in the cannabidiol oral solution is a synthetic pharmaceutical-grade cannabidiol produced by INSYS Manufacturing LLC (Chandler, AZ, USA), according to Current Good Manufacturing Practice. The three dosing cohorts were evaluated sequentially, starting with the $10-\mathrm{mg} / \mathrm{kg}$ cohort. Enrollment of approximately 20 patients per cohort was targeted, with each cohort consisting of five infants (aged 1 to $<2$ years), nine children (aged 2 to $<12$ years), and six adolescents (aged 12 to $\leq 17$ years). Based on compatibility testing conducted by the sponsor, patients were allowed to receive cannabidiol oral solution via a gastronomy tube, if needed.

On day 1 , patients received a single dose (morning; 5,10 , or $20 \mathrm{mg} / \mathrm{kg}$ ) followed by a preset volume of water or clear liquid; no doses were received on days 2 and 3, and then multiple doses (morning and evening dose) were received on days 4 through $10(10-, 20-$, or $40-\mathrm{mg} / \mathrm{kg}$ total daily dose split into two daily doses; Fig. 1). The parent(s) or caregiver(s) of each eligible patient were offered the opportunity for all visits to be completed in an inpatient setting if they preferred. Otherwise, the following inpatient schedule was used: patients were admitted as inpatients on the final screening day (day 0 ) and remained in the medical facility at least until they received the morning dose on day 8. Patients were readmitted as inpatients on the morning of day 10 and released on the morning of day 11 (first day of the follow-up period) after completing the study assessments.

\subsection{Study Assessments}

Pharmacokinetic sampling schemes were adjusted based on age to avoid excessive blood loss. All blood samples were collected in 2-mL potassium ethylene diamine tetra acetic acid $\left(\mathrm{K}_{2}\right.$-EDTA) plasma tubes for patients aged $<2$ years and in 4-mL $\mathrm{K}_{2}$-EDTA plasma tubes for patients aged

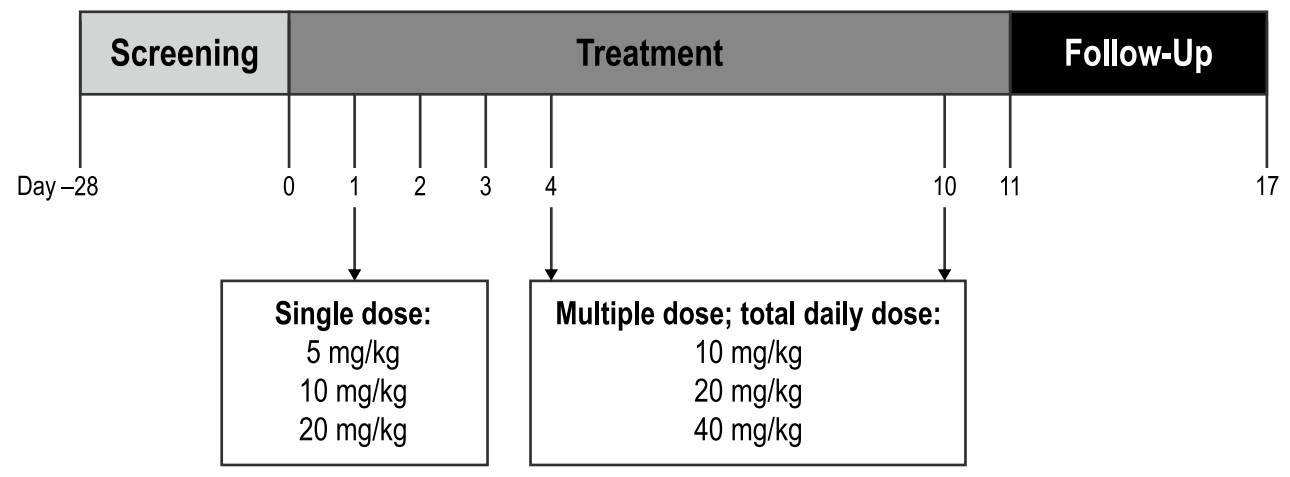

Fig. 1 Study design. After screening period, patients were randomly assigned to three dosing cohorts of cannabidiol oral solution (cohort $1: 10 \mathrm{mg} / \mathrm{kg} / \mathrm{day}$; cohort 2: $20 \mathrm{mg} / \mathrm{kg} / \mathrm{day}$; and cohort $3: 40 \mathrm{mg} / \mathrm{kg} /$ day). Patients received a single dose $(5 \mathrm{mg} / \mathrm{kg}, 10 \mathrm{mg} / \mathrm{kg}$, or $20 \mathrm{mg} /$ $\mathrm{kg}$, respectively) on day 1 , and no drug was given on days 2 and 3 . Patients received $5 \mathrm{mg} / \mathrm{kg}, 10 \mathrm{mg} / \mathrm{kg}$, or $20 \mathrm{mg} / \mathrm{kg}$ twice daily $(10$ $\mathrm{mg} / \mathrm{kg} /$ day, $20 \mathrm{mg} / \mathrm{kg} / \mathrm{day}$ or $40 \mathrm{mg} / \mathrm{kg} /$ day, respectively) from day 4 to day 10 
$\geq 2$ years. For the PK analysis of cannabidiol and its primary metabolite 7-hydroxy-cannabidiol (7-OH cannabidiol) concentrations, serial blood samples were collected on day 1 pre-dose (for patients aged 2 to $<6$ years and patients aged 6 to $\leq 17$ years) and at 2, 4, 8, and $12 \mathrm{~h}$ post-dose (for all patients; Table 1). Additional samples were obtained at 1 , 3, 16, 24 (day 2), and $48 \mathrm{~h}$ (day 3) after initial dosing on day 1 in patients aged 2 to $<6$ years and patients aged 6 to $\leq 17$ years. Samples were also taken at 6,36 , and $72 \mathrm{~h}$ (before the scheduled morning cannabidiol dose on day 4) after initial dosing on day 1 in patients aged 6 to $\leq 17$ years. On day 10 (multiple dose), plasma was collected pre-dose and at 2, 4, 8, and $12 \mathrm{~h}$ (before administration of the second daily dose) post-dose in all patients. On day 10 , additional samples were collected at $6 \mathrm{~h}$ (age 6 to $\leq 17$ years only), and 1,3 , and $24 \mathrm{~h}$ post-dose in patients aged $\geq 2$ years (Table 1). In addition, samples for trough cannabidiol and 7-OH cannabidiol concentrations were evaluated on day 6 (for patients aged 12 to $\leq 17$ years), day 8 (for patients aged 2 to $\leq 17$ years), and day 9 (for patients aged 6 to $\leq 17$ years) prior to the morning dose.

On plasma collection days, with the exception of preset volumes of water or clear liquid to be consumed immediately after drug administration, patients were not to have liquid or solid food for $1 \mathrm{~h}$ (age $<2$ years) or $2 \mathrm{~h}$ (age $\geq 2$ years) before and after drug administration.

Cannabidiol has been shown to impact the metabolism of clobazam in pediatric patients, resulting in elevated plasma concentrations of norclobazam, an active metabolite of clobazam [21, 26]. Therefore, plasma concentrations of clobazam and norclobazam were determined on days 1 , 8 , and 10 before dosing in patients aged $\geq 2$ years who were receiving clobazam as part of their established antiepileptic drug regimen treatment.

Plasma concentrations of cannabidiol and 7-OH cannabidiol were determined using an API 5000 ${ }^{\mathrm{TM}}$ liquid chromatography-mass spectrometry system (AB Sciex, Concord, ON, Canada) equipped with a high-performance liquid chromatography column. The procedure has been validated to detect cannabidiol and 7-OH cannabidiol concentrations ranging from 0.100 to $50.0 \mathrm{ng} / \mathrm{mL}$, based on the analysis of $0.2 \mathrm{~mL}$ of plasma. Clobazam and norclobazam concentrations were analyzed with a validated assessment range from 1.00 to $500 \mathrm{ng} / \mathrm{mL}$, based on the analysis of $0.1 \mathrm{~mL}$ of plasma. For both cannabidiol and clobazam, the quantitation was performed using a weighted $1 / x^{2}$ linear least-squares regression analysis generated from calibration standards. Quality control samples from high, medium, and low pools were processed with each sample run; the sample run was validated when at least two-thirds of the qualifying quality control samples were within $15 \%$ of their theoretical values and $\geq 50 \%$ of quality control samples at each level met this criterion.

Safety assessments, including monitoring of treatmentemergent AEs and vital signs, were conducted throughout the study. Electrocardiogram measurements were obtained

Table 1 Schedule of pharmacokinetic sampling

\begin{tabular}{|c|c|c|c|c|c|c|c|c|c|}
\hline \multirow{2}{*}{$\begin{array}{l}\text { Morning } \\
\text { dose }\end{array}$} & \multicolumn{3}{|c|}{ Day 1 serial sampling } & \multirow{2}{*}{$\begin{array}{l}\text { Day } 6^{\mathrm{a}} \\
12 \\
\text { to } \leq 17 \text { years }\end{array}$} & \multirow{2}{*}{$\begin{array}{l}\text { Day } 8^{a} \\
2 \\
\text { to } \leq 17 \text { years }\end{array}$} & \multirow{2}{*}{$\begin{array}{l}\text { Day } 9^{a} \\
6 \\
\text { to } \leq 17 \text { years }\end{array}$} & \multicolumn{3}{|c|}{ Day 10 serial sampling } \\
\hline & $\begin{array}{l}1 \\
\text { to }<2 \text { years }\end{array}$ & $\begin{array}{l}2 \\
\text { to }<6 \text { years }\end{array}$ & $\begin{array}{l}6 \\
\text { to } \leq 17 \text { years }\end{array}$ & & & & $\begin{array}{l}1 \\
\text { to }<2 \text { years }\end{array}$ & $\begin{array}{l}2 \\
\text { to }<6 \text { years }\end{array}$ & $\begin{array}{l}6 \\
\text { to } \leq 17 \text { years }\end{array}$ \\
\hline Pre-dose $(0)^{\mathrm{b}}$ & & $\mathrm{X}$ & $\mathrm{X}$ & $\mathrm{X}$ & $\mathrm{X}$ & $\mathrm{X}$ & $\mathrm{X}$ & $\mathrm{X}$ & $\mathrm{X}$ \\
\hline $1 \mathrm{~h}$ & & $\mathrm{X}$ & $X$ & & & & & $X$ & $X$ \\
\hline $2 \mathrm{~h}$ & $X$ & $X$ & $X$ & & & & $X$ & $X$ & $X$ \\
\hline $3 \mathrm{~h}$ & & $\mathrm{X}$ & $\mathrm{X}$ & & & & & $X$ & $\mathrm{X}$ \\
\hline $4 \mathrm{~h}$ & $\mathrm{X}$ & $\mathrm{X}$ & $\mathrm{X}$ & & & & $\mathrm{X}$ & $X$ & $\mathrm{X}$ \\
\hline $6 \mathrm{~h}$ & & & $\mathrm{X}$ & & & & & & $\mathrm{X}$ \\
\hline $8 \mathrm{~h}$ & $X$ & $\mathrm{X}$ & $X$ & & & & $X$ & $X$ & $X$ \\
\hline $12 \mathrm{~h}$ & $X$ & $X$ & $X$ & & & & $X$ & $X$ & $X$ \\
\hline $16 \mathrm{~h}$ & & $\mathrm{X}$ & $\mathrm{X}$ & & & & & & \\
\hline 24 h (day 2) & & $X$ & $\mathrm{X}$ & & & & & $X$ & $\mathrm{X}$ \\
\hline $36 \mathrm{~h}$ & & & $\mathrm{X}$ & & & & & & \\
\hline 48 h (day 3) & & $\mathrm{X}$ & $\mathrm{X}$ & & & & & & \\
\hline $72 \mathrm{~h}(\text { day } 4)^{\mathrm{b}}$ & & & $\mathrm{X}$ & & & & & & \\
\hline
\end{tabular}

Patients received a single dose on day 1 , no dose on days 2 and 3, and twice-daily dosing on days 4-10

${ }^{\text {a }}$ Samples were collected pre-dose for trough cannabidiol concentrations

${ }^{\mathrm{b}}$ Samples were collected prior to cannabidiol dosing 
at screening and on days $1,4,8$, and 11 before treatment administration. Clinical serum chemistry assessments included alanine aminotransferase, albumin, alkaline phosphatase, aspartate aminotransferase, bicarbonate, bilirubin (total and direct), blood urea nitrogen, calcium, chloride, creatinine, follicle-stimulating hormone, glucose, phosphorus, potassium, protein (total), sodium, and uric acid concentrations.

\subsection{Data Analyses}

The PK population included all patients who received at least one dose of the study medication and had at least one post-dose cannabidiol and/or 7-OH cannabidiol plasma concentration measurement. The safety population included all patients who received at least one dose of the study medication. Pharmacokinetic analyses were performed using Phoenix ${ }^{\circledR}$ WinNonlin ${ }^{\circledR}$ Version 6.4 (Certara L.P., Princeton, NJ, USA) or SAS ${ }^{\circledR}$ Version 9.4 or higher (SAS Institute, Inc., Cary, NC, USA). A non-compartmental method was used to derive all PK parameters. Pharmacokinetic data were summarized by study day and scheduled time and stratified by dose using descriptive statistics (sample size $[n]$, mean, standard deviation, coefficient of variation, median, minimum, maximum, and geometric mean and geometric coefficient of variation [as appropriate for PK parameters]). All observed data were analyzed; missing values were not imputed.

\section{Results}

Of the 84 patients screened, 61 patients $(72.6 \%)$ were enrolled and randomly assigned to receive cannabidiol oral solution (cohort 1 [10 mg/kg/day], $n=20$; cohort 2 [20 mg/ $\mathrm{kg} / \mathrm{day}], n=20$, and cohort 3 [40 $\mathrm{mg} / \mathrm{kg} / \mathrm{day}], n=21$ ). Background antiepileptic drugs and concomitant medications were the most common eligibility-related reasons for screen failure. All 61 patients were included in the PK and safety populations and completed the study. The age group composition of all cohorts was similar (infants, $n=5$ [all cohorts]; children, $n=9$ [cohorts 1 and 2] or $n=10$ [cohort 3]; and adolescents, $n=6$ [all cohorts]) as was mean age (7.5-7.8 years; Table 2) and mean weight (24.3-29.7 kg; Table 2).

\subsection{Pharmacokinetics}

\subsubsection{Cannabidiol}

Single-dose administration of cannabidiol oral solution showed inter-individual variability with differences in systemic exposure between cohorts (Table 3 ). The median time to the maximum plasma concentration of cannabidiol after a single dose for all cohorts ranged from 2 to $4 \mathrm{~h}$ post-dose, indicating slow absorption of cannabidiol oral solution with a broad absorption phase when given without food. No doserelated differences in geometric mean terminal half-life were observed after a single dose.

After the administration of multiple doses of cannabidiol (day 10), there was a trend toward increased exposure, defined as area under the concentration-time curve in plasma during the dosing interval $\left(\mathrm{AUC}_{(0-\tau)}\right)$, that was associated with increased cannabidiol oral solution dosing across cohorts (Fig. 2). After approximately 2-6 days of twice-daily dosing, apparent steady-state concentrations of cannabidiol were achieved. The median time to the maximum plasma concentration ranged between 2 and $3 \mathrm{~h}$ and was independent of dose. Maximum plasma concentration $\left(C_{\text {max }}\right)$ and total cannabidiol exposure $\left(\mathrm{AUC}_{(0-\tau)}\right)$ increased proportionally with dose, such that an approximate four-fold increase was observed over the $10-$ to $40-\mathrm{mg} / \mathrm{kg} /$ day dose range. Apparent clearance was dose independent (Table 3). An accumulation of cannabidiol was observed after up to 7 days of twice-daily dosing. Accumulation was 1.1- to 11.8fold based on $C_{\max }$ and 1.8- to 16.5-fold across all doses, based on the area under the concentration-time curve.

\subsubsection{7-OH Cannabidiol}

Pharmacokinetic results of the primary metabolite, 7-OH cannabidiol, generally reflected those observed for cannabidiol (Table 4; ESM). The geometric mean molar ratios of 7-OH cannabidiol/cannabidiol exposures across age strata ranged from 0.38 to 1.07 for $C_{\max }$ on day 1 and from 0.49 to 0.85 for $C_{\max }$ on day 10, and from 0.54 to 1.36 for total exposure $\left(\mathrm{AUC}_{(0-\infty)}\right.$ and $\left.\mathrm{AUC}_{(0-12)}\right)$ on day 1 and from 0.65 to 0.98 for total exposure $\left(\mathrm{AUC}_{(0-12)}\right)$ on day 10 . The ratio of 7-OH cannabidiol to the parent compound (cannabidiol) was not affected by cannabidiol dose or patient age. The geometric mean of the terminal half-life of 7-OH cannabidiol was similar to or shorter than that of cannabidiol (Table 4).

\subsubsection{Age Assessment}

The mean (SD) plasma cannabidiol concentration-time profiles following multiple-dose administrations of cannabidiol oral solution (cohort 1 [10 mg/kg/day], cohort 2 [20 mg/kg/ day], and cohort 3 [40 mg/kg/day]) by age categories are shown in Fig. 3a-c. Statistical comparisons for age effects on cannabidiol exposure after multiple doses are presented in Table 5. The point estimates for infants vs. children or for infants vs. adolescents for $C_{\max }$ and $\mathrm{AUC}_{(0-\tau)}$ ranged from 38.7 to $46.8 \%$. There were no major differences between children and adolescents. At the lower dose levels $(20 \mathrm{mg} /$ $\mathrm{kg} /$ day or $10 \mathrm{mg} / \mathrm{kg} /$ day), exposure in infants was also lower 
Table 2 Baseline demographic and disease characteristics for pediatric patients with epilepsy treated with cannabidiol

\begin{tabular}{|c|c|c|c|c|}
\hline Characteristic & $\begin{array}{l}\text { Cohort } 1 \\
10 \mathrm{mg} / \mathrm{kg} / \text { day }(n=20)\end{array}$ & $\begin{array}{l}\text { Cohort } 2 \\
20 \mathrm{mg} / \mathrm{kg} / \text { day }(n=20)\end{array}$ & $\begin{array}{l}\text { Cohort } 3 \\
40 \mathrm{mg} / \mathrm{kg} / \text { day }(n=21)\end{array}$ & All cohorts $(N=61)$ \\
\hline Age, mean (SD), years & $7.5(5.3)$ & $7.7(5.2)$ & $7.8(5.4)$ & $7.6(5.2)$ \\
\hline Infants $(n=5)$ & $1.0(0.0)$ & $1.0(0.0)$ & $1.0(0.0)$ & \\
\hline Children $(n=9)$ & $6.9(3.1)$ & $7.2(2.4)$ & $7.2(2.7)^{\mathrm{a}}$ & \\
\hline Adolescents $(n=6)$ & $13.7(1.8)$ & $13.8(1.5)$ & $14.5(1.6)$ & \\
\hline Male sex, $n(\%)$ & $10(50.0)$ & $13(65.0)$ & $10(47.6)$ & $33(54.1)$ \\
\hline \multicolumn{5}{|l|}{ Race, $n(\%)$} \\
\hline White & $16(80.0)$ & $16(80.0)$ & $18(85.7)$ & $50(82.0)$ \\
\hline Black or African American & $1(5.0)$ & $1(5.0)$ & $1(4.8)$ & $3(4.9)$ \\
\hline Other $^{b}$ & $3(15.0)$ & $3(15.0)$ & $2(9.5)$ & $8(13.1)$ \\
\hline Weight, mean (SD), kg & $24.3(12.5)$ & $26.6(18.4)$ & $29.7(20.6)$ & $26.9(17.4)$ \\
\hline Infants $(n=5)$ & $12.1(2.3)$ & $10.7(1.0)$ & $10.9(1.5)$ & \\
\hline Children $(n=9)$ & $23.3(9.2)$ & $21.7(6.7)$ & $24.9(12.3)^{\mathrm{a}}$ & \\
\hline Adolescents $(n=6)$ & $35.8(12.1)$ & $47.2(20.2)$ & $53.4(18.5)$ & \\
\hline $\begin{array}{l}\text { Seizures/d during } 14-28 \text { days } \\
\text { before day } 0, \text { mean }(\mathrm{SD})\end{array}$ & $13.7(23.5)^{\mathrm{c}}$ & $10.4(16.6)$ & $23.7(31.4)$ & $16.1(25.0)^{\mathrm{d}}$ \\
\hline
\end{tabular}

$S D$ standard deviation

${ }^{\mathrm{a}} n=10$

${ }^{\mathrm{b}}$ Includes patients who identified as American Indian, Alaska Native, Asian, Native Hawaiian, or other Pacific Islander

${ }^{\mathrm{c}} n=19$

${ }^{\mathrm{d}} n=60$

Table 3 Key plasma cannabidiol pharmacokinetic parameters in pediatric patients with epilepsy

\begin{tabular}{|c|c|c|c|c|c|c|c|c|}
\hline \multirow{2}{*}{$\begin{array}{l}\text { Cannabidiol } \\
\text { oral solution } \\
\text { cohort }\end{array}$} & \multicolumn{4}{|c|}{ Day 1 (single dose) } & \multicolumn{4}{|c|}{ Day 10 (multiple dose) } \\
\hline & $\begin{array}{l}T_{\text {max }}, \mathrm{h}: \text { median } \\
\text { (range) }\end{array}$ & $t_{1 / 2}, \mathrm{~h}^{\mathrm{a}}$ & $\mathrm{AUC}_{(0-12)}, \mathrm{ng} \cdot \mathrm{h} / \mathrm{mL}^{\mathrm{a}}$ & $C_{\max }, \mathrm{ng} / \mathrm{mL}^{\mathrm{a}}$ & $\begin{array}{l}T_{\max }, \mathrm{h}: \text { median } \\
\text { (range) }\end{array}$ & $\begin{array}{l}\mathrm{AUC}_{(0-\tau)}, \mathrm{ng} \cdot \mathrm{h} / \\
\mathrm{mL}^{\mathrm{a}}\end{array}$ & $C_{\max }, \mathrm{ng} / \mathrm{mL}^{\mathrm{a}}$ & CLss/F, L/h/ $/ \mathrm{kg}^{\mathrm{a}}$ \\
\hline $\begin{array}{c}10 \mathrm{mg} / \mathrm{kg} / \text { day } \\
(n=20)\end{array}$ & $2.6(1.0-8.0)$ & $26.4,31.3(74.9)$ & $122,173.9(103.3)$ & $29.12,59.03(169.4)$ & $3.0(1.0-4.2)$ & $507.0,581.6(48.7)$ & $91.0,119.6(87.8)$ & $9.9,12.1(88.0)$ \\
\hline $\begin{array}{c}20 \mathrm{mg} / \mathrm{kg} / \text { day } \\
(n=20)\end{array}$ & $4.0(1.0-8.1)$ & $29.6,33.5(44.7)$ & $243.6,507.1(135.6)$ & $47.19,110.5(128.8)$ & $2.0(0.0-6.0)$ & $836.0,1098$ (88.9) & $126.0,220.0(134.0)$ & $12.3,15.3(63.9)$ \\
\hline $\begin{array}{c}40 \mathrm{mg} / \mathrm{kg} / \text { day } \\
(n=21)\end{array}$ & $3.2(1.0-24.0)$ & $19.5,21.6(48.7)$ & $473.5,914.5(126.3)$ & $103.7,256.9(136.9)$ & $3.0(0.0-6.0)$ & $2108,2708(66.1)$ & $314.5,426.8(76.8)$ & $9.5,13.2(97.5)$ \\
\hline
\end{tabular}

$A U C_{(0-12)}$ area under the concentration-time curve in plasma from time 0 to $12 \mathrm{~h}, A U C_{(0-\tau)}$ area under the concentration-time curve in plasma during the dosing interval, $C L s s / F$ apparent total body clearance after oral administration at steady state, $C_{\max }$ maximum plasma concentration, $C V \%$ coefficient of variation, $t_{1 / 2}$ apparent terminal half-life, $T_{\max }$ time to maximum plasma concentration

${ }^{a}$ Values given are geometric mean, mean, $(\mathrm{CV} \%)$

than in adolescents; there were no consistent trends for children. The $90 \%$ confidence intervals contained $100 \%$ for most of the age category comparisons at the lower dose levels.

\subsubsection{Influence of Clobazam Use}

Approximately half of the patients $(52.5 \%)$ in the study received concomitant clobazam. In patients receiving clobazam plus cannabidiol oral solution at a dose of $40 \mathrm{mg} /$ $\mathrm{kg} / \mathrm{day}$, mean cannabidiol exposure on day 10 increased approximately 2.5 -fold compared with patients not receiving clobazam (geometric mean $\mathrm{AUC}_{(0-\tau)}, 3130 \mathrm{ng} \cdot \mathrm{h} / \mathrm{mL}$

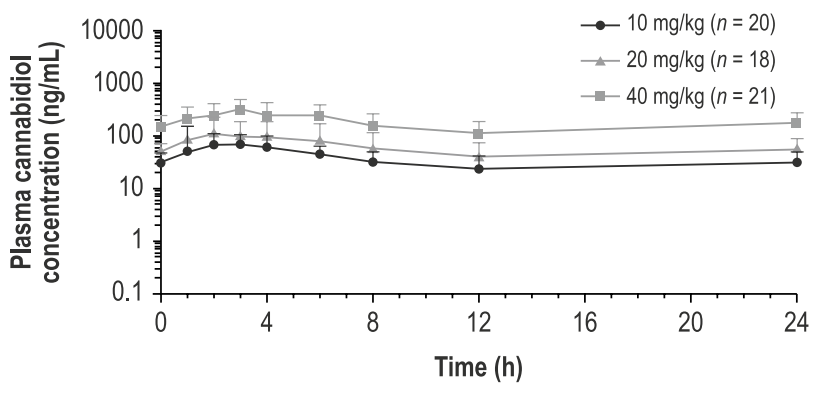

Fig. 2 Mean overall plasma cannabidiol concentration-time profile (semi-log scale) on day 10. Data shown are geometric means; error bars represent standard deviations 
Table 4 Key plasma 7-OH cannabidiol pharmacokinetic parameters in pediatric patients with epilepsy

\begin{tabular}{|c|c|c|c|c|c|c|c|c|}
\hline \multirow{2}{*}{$\begin{array}{l}\text { Cannabidiol } \\
\text { oral solution } \\
\text { cohort }\end{array}$} & \multicolumn{4}{|c|}{ Day 1 (single dose) } & \multicolumn{4}{|c|}{ Day 10 (multiple dose) } \\
\hline & $\begin{array}{l}T_{\max }, \mathrm{h}: \text { median } \\
\text { (range) }\end{array}$ & $t_{1 / 2}, \mathrm{~h}^{\mathrm{a}}$ & $\mathrm{AUC}_{(0-12)}, \mathrm{ng} \cdot \mathrm{h} / \mathrm{mL}^{\mathrm{a}}$ & $C_{\max }, \mathrm{ng} / \mathrm{mL}^{\mathrm{a}}$ & $\begin{array}{l}T_{\max }, \mathrm{h}: \\
\text { median (range) }\end{array}$ & $\mathrm{AUC}_{(0-\tau)}, \mathrm{ng} \cdot \mathrm{h} / \mathrm{mL}^{\mathrm{a}}$ & $C_{\max }, \mathrm{ng} / \mathrm{mL}^{\mathrm{a}}$ & $\mathrm{MR}_{\mathrm{AUC}(0-\tau)}{ }^{\mathrm{a}}$ \\
\hline $\begin{array}{c}10 \mathrm{mg} / \mathrm{kg} / \text { day } \\
(n=20)\end{array}$ & $2.6(1.0-6.1)$ & $18.4,19.7(38.8)$ & $104.0,124.4(64.4)$ & $22.03,28.71(93.1)$ & $2.1(1.0-4.1)$ & $428.3,513.4(52.4)$ & $65.6,79.4(51.4)$ & $0.80,0.88(46.4)$ \\
\hline $\begin{array}{c}20 \mathrm{mg} / \mathrm{kg} / \text { day } \\
(n=20)\end{array}$ & $4.0(1.0-12.0)$ & $25.6,31.8(76.3)$ & $202.4,329.8(122.1)$ & $34.56,61.89(117.8)$ & $2.0(1.0-6.0)$ & $658.8,832.8(81.1)$ & $97.1,136.6(103.1)$ & $0.75,0.79(30.0)$ \\
\hline $\begin{array}{c}40 \mathrm{mg} / \mathrm{kg} / \text { day } \\
(n=21)\end{array}$ & $3.1(1.0-12.1)$ & $14.214 .8(29.5)$ & $381.9,646.7(137.1)$ & $71.7,140.9(149.0)$ & $2.0(0.0-5.9)$ & $1688,2165(64.9)$ & $217.7,286.1(70.6)$ & $0.76,0.87(49.5)$ \\
\hline
\end{tabular}

$A U C_{(0-12)}$ area under the concentration-time curve in plasma from time 0 to $12 \mathrm{~h}, A U C_{0-\tau}$ area under the concentration-time curve in plasma during the dosing interval, $C_{\max }$ maximum plasma concentration, $C V \%$ coefficient of variation, $M R_{A U C(0-\operatorname{tau})}$ metabolite to parent (7-OH canna$\mathrm{bidiol} / \mathrm{cannabidiol)}$ ratio of $\mathrm{AUC}_{(0-\mathrm{tau})}, t_{1 / 2}$ apparent terminal half-life, $T_{\max }$ time to maximum plasma concentration

${ }^{\mathrm{a}}$ Values given are geometric mean, mean, $(\mathrm{CV} \%)$

(a)

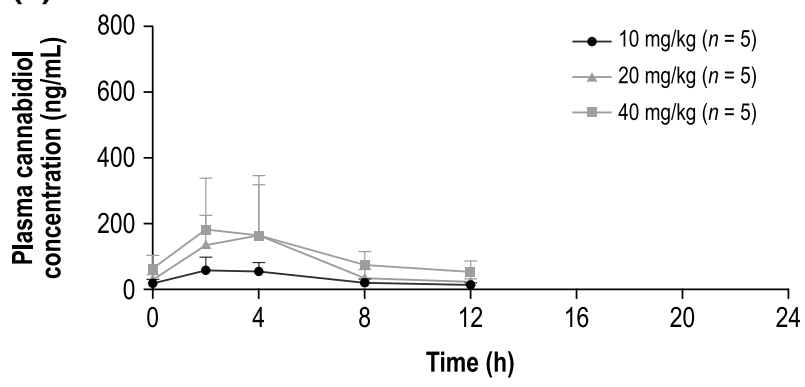

(b)

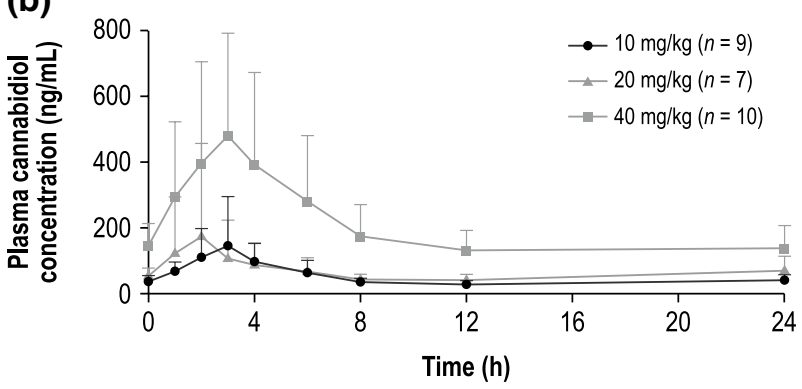

(c)

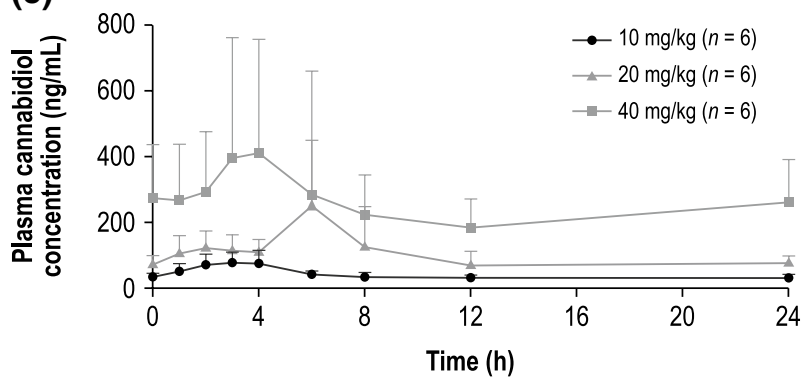

Fig. 3 Mean plasma cannabidiol concentration-time profile on multiple-dose on day 10 in $\mathbf{a}$ infants, $\mathbf{b}$ children ${ }^{\mathrm{a}}$, and $\mathbf{c}$ adolescents. Data shown are geometric means; error bars represent standard deviations. ${ }^{a}$ For cohort 2 ( $\left.20 \mathrm{mg} / \mathrm{kg} / \mathrm{day}\right)$, two children missed one or more doses between the evening of day 8 and assessment at day 9 and were not included in the analysis for this cohort vs. $1245 \mathrm{ng} \cdot \mathrm{h} / \mathrm{mL}$, respectively; Table 6), indicating a drug-drug interaction with clobazam. The $C_{\max }$ of cannabidiol was approximately 2.4 -fold higher in patients receiving clobazam compared with patients not receiving clobazam. Similarly, a trend for increased 7-OH cannabidiol concentrations with clobazam administration was seen with an approximately 3.06-fold higher $C_{\max }$ and a 3.14-fold higher $\mathrm{AUC}_{(0-\tau)}$ in patients receiving clobazam compared with patients not receiving clobazam. On day 10, mean plasma clobazam concentrations were increased 1.7- and 2.2-fold in patients receiving clobazam concomitantly with cannabidiol oral solution of $40 \mathrm{mg} / \mathrm{kg} / \mathrm{day}$ compared with $10 \mathrm{mg} / \mathrm{kg} / \mathrm{day}$ and $20 \mathrm{mg} / \mathrm{kg} /$ day $(857 \mathrm{ng} / \mathrm{mL}$ vs. $500 \mathrm{ng} / \mathrm{mL}$ and $390 \mathrm{ng} /$ $\mathrm{mL}$ ), respectively. Similarly, mean plasma norclobazam concentrations on day 10 were increased 1.3- and 1.9-fold in patients receiving clobazam concomitantly with cannabidiol oral solution of $40 \mathrm{mg} / \mathrm{kg} /$ day compared with $10 \mathrm{mg} /$ $\mathrm{kg} /$ day and $20 \mathrm{mg} / \mathrm{kg} /$ day $(6111 \mathrm{ng} / \mathrm{mL}$ vs. $4750 \mathrm{ng} / \mathrm{mL}$ and $3224 \mathrm{ng} / \mathrm{mL}$ ), respectively. Additionally, cannabidiol appeared to increase clobazam and norclobazam concentrations in a dose-dependent manner, and mean clobazam and norclobazam concentrations were increased up to 2.8 -fold on day 10 (pre-dose) compared with day 1 (baseline, prior to administration of cannabidiol).

\subsection{Safety}

All doses of cannabidiol oral solution were generally well tolerated. Overall, the most common AEs included somnolence (21.3\%), anemia (18.0\%), and diarrhea (16.4\%; Table 7), and most AEs were mild (26.2\%) or moderate $(13.1 \%)$. The incidence of diarrhea, increased weight, somnolence, and psychomotor hyperactivity increased as the dose of cannabidiol oral solution increased. Of the 13 patients who reported somnolence, seven $(53.8 \%)$ were receiving the highest dose of cannabidiol oral solution $(40 \mathrm{mg} / \mathrm{kg} /$ day) and concomitant clobazam. An increase in alanine aminotransferase was reported in a 16-year-old male 
Table 5 Age effects of cannabidiol exposure after multiple-dose administration

\begin{tabular}{|c|c|c|c|}
\hline Cohort & Geometric LS mean & Pairwise comparison & Ratio, \% (90\% CI) \\
\hline \multicolumn{4}{|c|}{$\mathrm{AUC}_{(0-\tau)}, \mathrm{ng} \cdot \mathrm{h} / \mathrm{mL}(95 \% \mathrm{CI})$} \\
\hline \multicolumn{4}{|l|}{ Cohort $1,10 \mathrm{mg} / \mathrm{kg} /$ day } \\
\hline Infants $(n=5)$ & $335.7(197.8-569.8)$ & Infants vs. children & $52.73(30.26-91.87)$ \\
\hline Children $(n=8)$ & $636.8(419.2-967.3)$ & Infants vs. adolescents & 63.64 (35.29-114.79) \\
\hline Adolescents $(n=6)$ & $527.5(325.5-854.9)$ & Children vs. adolescents & $120.71(71.33-204.26)$ \\
\hline \multicolumn{4}{|l|}{ Cohort 2, $20 \mathrm{mg} / \mathrm{kg} /$ day } \\
\hline Infants $(n=4)^{\mathrm{a}}$ & $746.1(345.6-1611)$ & Infants vs. children & $113.65(51.46-250.99)$ \\
\hline Children $(n=7)$ & $656.5(366.9-1175)$ & Infants vs. adolescents & 62.39 (27.59-141.08) \\
\hline Adolescents $(n=6)$ & 1196 (637.9-2242) & Children vs. adolescents & $54.90(27.17-110.91)$ \\
\hline \multicolumn{4}{|l|}{ Cohort $3,40 \mathrm{mg} / \mathrm{kg} /$ day } \\
\hline Infants $(n=5)$ & 1068 (545.4-2090) & Infants vs. children & $42.36(21.48-83.53)$ \\
\hline Children $(n=10)$ & $2520(1567-4053)$ & Infants vs. adolescents & $38.67(18.26-81.93)$ \\
\hline Adolescents $(n=6)$ & $2761(1495-5097)$ & Children vs. adolescents & $91.30(48.13-173.18)$ \\
\hline \multicolumn{4}{|l|}{$C_{\max }, \mathrm{ng} / \mathrm{mL}(95 \% \mathrm{CI})$} \\
\hline \multicolumn{4}{|l|}{ Cohort $1,10 \mathrm{mg} / \mathrm{kg} /$ day } \\
\hline Infants $(n=5)$ & $55.89(27.21-114.8)$ & Infants vs. children & $47.74(22.78-100.07)$ \\
\hline Children $(n=9)$ & $117.1(68.47-200.2)$ & Infants vs. adolescents & $59.70(26.73-133.33)$ \\
\hline Adolescents $(n=6)$ & $93.61(48.53-180.6)$ & Children vs. adolescents & $125.06(62.15-251.66)$ \\
\hline \multicolumn{4}{|l|}{ Cohort 2, $20 \mathrm{mg} / \mathrm{kg} /$ day } \\
\hline Infants $(n=4)^{\mathrm{a}}$ & $128.0(41.81-392.0)$ & Infants vs. children & $127.54(40.30-403.64)$ \\
\hline Children $(n=7)$ & $100.4(43.08-233.9)$ & Infants vs. adolescents & $78.68(24.02-257.73)$ \\
\hline Adolescents $(n=6)$ & $162.7(65.25-405.8)$ & Children vs. adolescents & $61.69(22.19-171.54)$ \\
\hline \multicolumn{4}{|l|}{ Cohort $3,40 \mathrm{mg} / \mathrm{kg} /$ day } \\
\hline Infants $(n=5)$ & $162.0(78.57-334.0)$ & Infants vs. children & $39.17(18.85-81.38)$ \\
\hline Children $(n=10)$ & $413.6(248.0-689.9)$ & Infants vs. adolescents & $46.80(20.85-105.05)$ \\
\hline Adolescents $(n=6)$ & $346.1(178.8-670.0)$ & Children vs. adolescents & $119.49(59.96-238.12)$ \\
\hline
\end{tabular}

$A U C_{(0-\tau)}$ area under the concentration-time curve in plasma during the dosing interval, $C I$ confidence interval, $C_{\max }$ maximum plasma concentration, $L S$ least-squares

${ }^{a}$ One patient in the infants group had a much higher exposure than others

individual receiving cannabidiol oral solution of $40 \mathrm{mg} / \mathrm{kg} /$ day; the patient had a slightly elevated alanine aminotransferase level (normal range: 5-30 U/L) at screening (43 U/L), which increased to $102 \mathrm{U} / \mathrm{L}$ on day 8 and decreased to $68 \mathrm{U} / \mathrm{L}$ by day 11 . The reported AE of "alanine aminotransferase increased" was of moderate severity and its relationship to the study drug was considered to be "probable". The $\mathrm{AE}$ resolved without any action, and the patient completed the study without any interruption in dose administration.

Three serious treatment-emergent AEs were reported (thrombophlebitis, apnea, and skin rash). Thrombophlebitis and apnea were considered by the investigator to be unrelated to the study drug; the skin rash was considered probably related to the study drug. The skin rash was reported by a 16-year-old male individual receiving $40 \mathrm{mg} / \mathrm{kg} /$ day of cannabidiol oral solution; the event occurred after the last scheduled dose (day 10), resulted in study discontinuation, and resolved with routine medical management. The serious AE of thrombophlebitis at the insertion site of a central catheter was reported in an 8-year-old female individual receiving $20 \mathrm{mg} / \mathrm{kg} /$ day of cannabidiol oral solution. The event of thrombophlebitis resulted in temporary discontinuation of study medication and resolved after enoxaparin therapy. The serious AE of apnea was reported in a 14-monthold male individual receiving $40 \mathrm{mg} / \mathrm{kg} /$ day of cannabidiol on day 10. This apneic episode was short $(<1 \mathrm{~min})$ and resolved with oxygen administration from a nasal cannula with no additional apnea episodes. No deaths were reported. No notable mean changes from baseline were observed in other clinical chemistry laboratory assessments, vital signs, or electrocardiogram readings.

\section{Discussion}

Previous studies have shown that cannabidiol is effective in controlling the frequency of seizures due to epilepsy of multiple etiologies in children and adults $[17-19,21,22]$. To our 
Table 6 Plasma cannabidiol exposure parameters at day 1 (single dose) and day 10 (multiple dose) by clobazam use (pharmacokinetic [PK] population)

\begin{tabular}{|c|c|c|c|c|c|c|}
\hline \multirow[t]{2}{*}{ PK parameters } & \multicolumn{3}{|c|}{ Day 1 serial sampling (geometric mean, mean, CV\%) } & \multicolumn{3}{|c|}{ Day 10 serial sampling (geometric mean, mean, CV\%) } \\
\hline & $10 \mathrm{mg} / \mathrm{kg} /$ day & $20 \mathrm{mg} / \mathrm{kg} /$ day & $40 \mathrm{mg} / \mathrm{kg} /$ day & $10 \mathrm{mg} / \mathrm{kg} /$ day & $20 \mathrm{mg} / \mathrm{kg} /$ day & $40 \mathrm{mg} / \mathrm{kg} /$ day \\
\hline \multicolumn{7}{|l|}{ With clobazam } \\
\hline$C_{\max }(\mathrm{ng} / \mathrm{mL})$ & $41.6,93.3(144.6)^{b}$ & $\begin{array}{c}52.9,117.9 \\
(129.1)^{\mathrm{b}}\end{array}$ & $\begin{array}{l}90.6,241.5 \\
(148.3)^{\mathrm{f}}\end{array}$ & $91.5,104.6(55.1)^{\mathrm{b}}$ & $\begin{array}{c}127.6,221.9 \\
(121.4)^{\mathrm{g}}\end{array}$ & $453.7,563.1(61.4)^{\mathrm{h}}$ \\
\hline $\begin{array}{l}\mathrm{AUC}_{(0-\tau)}(\mathrm{ng} \cdot \mathrm{h} / \\
\mathrm{mL})^{\mathrm{a}}\end{array}$ & $\begin{array}{c}171.2,246.4 \\
(93.1)^{\mathrm{b}}\end{array}$ & $\begin{array}{c}342.6,650.9 \\
(124.8)^{\mathrm{d}}\end{array}$ & $\begin{array}{c}446.8,960.5 \\
(138.7)^{\mathrm{f}}\end{array}$ & $\begin{array}{c}521.2,575.2 \\
(45.5)^{\mathrm{d}}\end{array}$ & $\begin{array}{c}867.1,1093 \\
(71.4)^{\mathrm{g}}\end{array}$ & $3130,3533(49.1)^{\mathrm{h}}$ \\
\hline $\mathrm{Cl} / \mathrm{F}(\mathrm{L} / \mathrm{h} / \mathrm{kg})$ & $19.2,24.2(61.2)^{\mathrm{c}}$ & $18.8,30.6(101.5)^{\mathrm{e}}$ & $18.2,32.8(109.7)^{\mathrm{g}}$ & $9.6,10.7(51.7)^{\mathrm{d}}$ & $12.1,15.2(74.7)^{\mathrm{g}}$ & $6.4,7.2(55.4)^{\mathrm{h}}$ \\
\hline \multicolumn{7}{|l|}{ Without clobazam } \\
\hline$C_{\max }(\mathrm{ng} / \mathrm{mL})$ & $20.4,24.8(68.2)^{\mathrm{b}}$ & $\begin{array}{l}42.1,103.1 \\
(135.2)^{\mathrm{b}}\end{array}$ & $\begin{array}{l}124.1,277.6 \\
(131.1)^{\mathrm{d}}\end{array}$ & $\begin{array}{c}90.5,134.7 \\
(103.6)^{\mathrm{b}}\end{array}$ & $\begin{array}{c}124.7,218.3 \\
(152.0)^{\mathrm{d}}\end{array}$ & $192.9,245.1(80.7)^{\mathrm{d}}$ \\
\hline $\begin{array}{l}\mathrm{AUC}_{(0-\tau)}(\mathrm{ng} \cdot \mathrm{h} / \\
\mathrm{mL})^{\mathrm{a}}\end{array}$ & $86.9,101.4(61.2)^{\mathrm{b}}$ & $\begin{array}{c}179.2,377.6 \\
(149.8)^{\mathrm{b}}\end{array}$ & $\begin{array}{c}511.6,853.2 \\
(110.5)^{\mathrm{d}}\end{array}$ & $\begin{array}{c}494.5,587.3 \\
(53.7)^{\mathrm{b}}\end{array}$ & $\begin{array}{c}809.3,1102 \\
(106.3)^{\mathrm{d}}\end{array}$ & $1245,1608(75.6)^{\mathrm{d}}$ \\
\hline $\mathrm{Cl} / \mathrm{F}(\mathrm{L} / \mathrm{h} / \mathrm{kg})$ & $35.9,38.1(41.0)^{\mathrm{c}}$ & $10.0,11.6(47.9)^{\mathrm{b}}$ & $22.2,28.3(67.2)^{\mathrm{e}}$ & $10.1,13.3(105.0)^{\mathrm{b}}$ & $12.6,15.3(57.3)^{\mathrm{d}}$ & $16.1,21.0(77.8)^{\mathrm{d}}$ \\
\hline \multicolumn{7}{|c|}{ Ratio of geometric means } \\
\hline$C_{\max }$ & 2.04 & 1.26 & 0.73 & 1.01 & 1.02 & 2.35 \\
\hline $\mathrm{AUC}_{(0-\tau)}$ & 1.97 & 1.91 & 0.87 & 1.05 & 1.07 & 2.51 \\
\hline $\mathrm{Cl} / \mathrm{F}$ & 0.53 & 1.88 & 0.82 & 0.95 & 0.96 & 0.40 \\
\hline
\end{tabular}

$A U C_{(0-\tau)}$ area under the concentration-time curve in plasma during the dosing interval for day $10, C l / F$ apparent total body clearance following oral administration, for day $10, C_{\max }$ maximum plasma concentration, $\mathrm{CV} \%$ coefficient of variation

${ }^{\mathrm{a}} \mathrm{AUC}_{(0-\mathrm{t})}$ is $\mathrm{AUC}_{(0-12)}$ for day 1 and $\mathrm{AUC}_{(0-\tau)}$ for day 10

${ }^{\mathrm{b}} n=10$

${ }^{c} n=6$

${ }^{\mathrm{d}} n=9$

$\mathrm{e}_{n=4}$

${ }^{\mathrm{f}} n=12$

$\mathrm{g}_{n}=8$

${ }^{\mathrm{h}} n=12$

knowledge, this is the first study of a synthetic cannabidiol formulation in humans and provides PK data in a pediatric population. We used a formulation that is $99.5 \%$ pure without the impurities, such as tetrahydrocannabinol and other cannabis molecules, which may be present in a non-US Food and Drug Administration-approved plant-based formulation. Additionally, synthetic cannabidiol used in the study has high chiral purity compared with plant material. It has been reported that the (+)-CBD isomer (synthetic) was more active than the (-)-CBD isomer (natural) in binding to CBD receptor $\mathrm{CB} 1$ and $\mathrm{CB} 2$.

In our study, patients received the study drug under fasting conditions. However, food has been reported to significantly increase cannabidiol exposure [27]. The food effect on cannabidiol absorption and the drug-drug interactions with other antiepileptic medications will need to be taken into account [5].

In this open-label, multiple ascending dose study of a pharmaceutical-grade synthetic cannabidiol oral solution in pediatric patients with treatment-resistant epilepsy, inter-individual variability in systemic exposure to cannabidiol was observed and 7-OH cannabidiol exhibited formation rate-limited PK parameters. Steady-state cannabidiol exposures occurred after approximately 2-6 days of treatment and appeared to increase in a dose-dependent manner. The total variability in cannabidiol exposures was higher after a single-dose administration on day 1 but decreased as patients received additional treatment doses (i.e., day 10). Increased exposures may partly represent the accumulation of cannabidiol over time. The doses of cannabidiol $(10 \mathrm{mg} /$ $\mathrm{kg} / \mathrm{day}, 20 \mathrm{mg} / \mathrm{kg} / \mathrm{day}$, and $40 \mathrm{mg} / \mathrm{kg} /$ day) tested in this study are similar to doses used in other clinical trials of plantbased cannabidiol formulations in pediatric populations and adults $[17,18,21]$.

Co-administration of clobazam was associated with increased cannabidiol exposure (2.5-fold increase in patients receiving clobazam compared with those not receiving clobazam) in the high-dose group (40 mg/kg/day). In addition, mean plasma clobazam and norclobazam concentrations were increased in patients receiving $40 \mathrm{mg} / \mathrm{kg} /$ day of 
Table 7 Adverse events (AEs) in pediatric patients with epilepsy treated with cannabidiol

\begin{tabular}{|c|c|c|c|c|}
\hline \multirow[t]{2}{*}{$\mathrm{AE}, n(\%)^{\mathrm{a}}$} & \multicolumn{4}{|c|}{ Cannabidiol oral solution } \\
\hline & All doses $(N=61)$ & $10 \mathrm{mg} / \mathrm{kg} /$ day $(n=20)$ & $20 \mathrm{mg} / \mathrm{kg} /$ day $(n=20)$ & $40 \mathrm{mg} / \mathrm{kg} /$ day $(n=21)$ \\
\hline Any AE & $39(63.9)$ & $13(65.0)$ & $9(45.0)$ & $17(81.0)$ \\
\hline Somnolence & $13(21.3)$ & $3(15.0)$ & $3(15.0)$ & $7(33.3)$ \\
\hline Anemia & $11(18.0)$ & $2(10.0)$ & $5(25.0)$ & $4(19.0)$ \\
\hline Diarrhea & $10(16.4)$ & $1(5.0)$ & $2(10.0)$ & $7(33.3)$ \\
\hline Flatulence & $5(8.2)$ & 0 & $2(10.0)$ & $3(14.3)$ \\
\hline Psychomotor hyperactivity & $5(8.2)$ & 0 & $2(10.0)$ & $3(14.3)$ \\
\hline Abdominal pain upper & $4(6.6)$ & $2(10.0)$ & $1(5.0)$ & $1(4.8)$ \\
\hline Catheter site pruritus & $3(4.9)$ & 0 & $2(10.0)$ & $1(4.8)$ \\
\hline Decreased appetite & $3(4.9)$ & $2(10.0)$ & 0 & $1(4.8)$ \\
\hline Seizure & $3(4.9)$ & $1(5.0)$ & $1(5.0)$ & $1(4.8)$ \\
\hline Vomiting & $3(4.9)$ & $2(10.0)$ & $1(5.0)$ & 0 \\
\hline Weight increased & $3(4.9)$ & 0 & $1(5.0)$ & $2(9.5)$ \\
\hline Ataxia & $2(3.3)$ & 0 & 0 & $2(9.5)$ \\
\hline Cough & $2(3.3)$ & $1(5.0)$ & $1(5.0)$ & 0 \\
\hline Contact dermatitis & $2(3.3)$ & 0 & $2(10.0)$ & 0 \\
\hline Dehydration & $2(3.3)$ & 0 & 0 & $2(9.5)$ \\
\hline Ecchymosis & $2(3.3)$ & 0 & $1(5.0)$ & $1(4.8)$ \\
\hline Insomnia & $2(3.3)$ & 0 & $1(5.0)$ & $1(4.8)$ \\
\hline Metabolic acidosis & $2(3.3)$ & 0 & 0 & $2(9.5)$ \\
\hline Pyrexia & $2(3.3)$ & $1(5.0)$ & 0 & $1(4.8)$ \\
\hline
\end{tabular}

${ }^{\text {a }}$ Reported in $\geq 2 \%$ of patients in overall population regardless of causality

cannabidiol oral solution compared with 10 and $20 \mathrm{mg} / \mathrm{kg} /$ day of cannabidiol oral solution. The bi-directional interaction between these two compounds could be because both are substrates for CYP3A4 even though other influencing factors such as other concomitant drugs, gender, and age may not be ruled out. In this study, the sample size for each age group per cohort was too small for additional analysis. Therefore, close serum concentration monitoring for both medications along with clinical monitoring may be needed in pediatric patients receiving clobazam concomitantly with cannabidiol.

Overall, synthetic cannabidiol oral solution was considered safe at all doses examined and generally well tolerated in this pediatric population. When compared with previous reports on plant-derived pharmaceutical formulations, the AEs reported in this study were generally similar [14, 28]. The incidence of some AEs (diarrhea, flatulence, somnolence, and psychomotor hyperactivity) appeared to be dose related, with higher cannabidiol oral solution doses eliciting more AEs. The event of somnolence occurred most often in patients taking concomitant clobazam, as previously reported with a plant-derived cannabidiol formulation in pediatric patients $[14,15,26,28]$.
This PK study of synthetic cannabidiol oral solution included different age groups (infants, children, and adolescents) and ascending doses, and evaluated PK parameters over an extended time period (up to 4 days after a single dose and 7 days after multiple doses). However, this study is limited by the small sample size per age group $(n=5-10)$, short treatment duration (10 days), sampling in patients aged 1 to $<2$ years that was sparser than that for patients aged 2 to $\leq 17$ years, high variability in cannabidiol exposure, drug-drug interaction between cannabidiol and clobazam, and differences in the distribution of concomitant drugs across age groups and cohorts. Furthermore, patients were receiving additional concomitant antiepileptic medications, which may have influenced the PK and safety profiles. Another limitation of this study is that plasma concentrations of concomitant antiepileptic drugs were not measured.

\section{Conclusion}

Steady-state cannabidiol exposures after administration of pharmaceutical-grade synthetic cannabidiol oral solution appeared to increase in a dose-dependent manner. Cannabidiol exposure varied among patients. Cannabidiol oral 
solution was generally safe at all doses studied and well tolerated in this pediatric population. Future studies are warranted to evaluate dose titration for efficacy and to assess the long-term safety profile of cannabidiol oral solution.

Acknowledgements Technical editorial and medical writing assistance was provided by Mary Beth Moncrief, Ph.D., and Jill Gee, Ph.D., Synchrony Medical Communications, LLC, West Chester, PA, USA. INS011-14-029 Study Investigators: Maria Roberta Cilio, Dennis Dlugos, Michael Kohrman, Ian Miller, Steven Phillips, Roshan Raja, J. Ben Renfroe, Colin M. Roberts, Steven P. Sparagana, and James W. Wheless. Data were presented in part at the 2017 Annual Meeting of the American Epilepsy Society, December 1-5, 2017, Washington, DC, USA.

\section{Compliance with Ethical Standards}

Ethical Approval The study protocol and amendments were approved by an institutional review board/ethics committee at each participating study center.

Informed Consent All patients and/or parent(s)/caregiver(s) provided written informed consent and assent (as applicable) at enrollment.

Funding This study was supported by INSYS Development Company, Inc. Support for technical editorial and medical writing assistance was provided by INSYS Development Company, Inc. Support for Open Access for this publication was provided by INSYS Development Company, Inc.

Conflict of interest James W. Wheless reports that his institution received research funding from Acadia Pharmaceuticals Inc., GW Pharmaceuticals, plc., INSYS Development Company, Inc., LivaNova, Mallinckrodt, National Institutes of Health, Neurelis, Inc., NeuroPace, Inc., Shainberg Foundation, Upsher-Smith Laboratories, LLC, and Zogenix, Inc.; and has been a consultant and/or on speaker's bureaus for CombiMatrix, Eisai Co., Ltd., GW Pharmaceuticals, plc., LivaNova, Lundbeck, Mallinckrodt, NeuroPace, Sun Pharmaceutical Industries, Ltd., Supernus Pharmaceuticals, Inc., and Upsher-Smith Laboratories, LLC. Dennis Dlugos reports that he received salary support from the National Institutes of Health, the Commonwealth of Pennsylvania Department of Health, and the Epilepsy Study Consortium, and he also received research program support for pre-study protocol development agreements with Bio-Pharm Solutions Inc., INSYS Development Company, Inc., and UCB, Inc. His institution received research support for clinical trials from INSYS Development Company, Inc. Ian Miller received honoraria and travel support from INSYS Development Company, Inc. and reports that his institution received study funding from INSYS Development Company, Inc. D. Alexander Oh was an employee of INSYS Development Company, Inc. and owns stock options for INSYS Development Company, Inc. Neha Parikh is an employee of INSYS Development Company, Inc. and owns stock options for INSYS Development Company, Inc. Steven Phillips reports that his institution received study funding from INSYS Development Company, Inc. J. Ben Renfroe reports that his institution received study funding from INSYS Development Company, Inc. Colin M. Roberts reports that his institution received study funding from INSYS Development Company, Inc. Isra Saeed reports that her institution received funding from INSYS Development Company, Inc. Steven P. Sparagana reports that his institution received study funding from INSYS Development Company, Inc. Jin Yu is an employee of INSYS Development Company, Inc. and owns stock options for INSYS Development Company, Inc. Maria Roberta Cilio reports that her institution received research support for clinical trials from INSYS Development Company, Inc; she also has been a consultant for BioMarin Pharmaceutical Inc., GW Pharmaceuticals plc., and Xenon Pharmaceuticals; and she received administrative support paid to her institution and drugs free of charge from GW Pharmaceuticals for previous studies.

Open Access This article is distributed under the terms of the Creative Commons Attribution-NonCommercial 4.0 International License (http://creativecommons.org/licenses/by-nc/4.0/), which permits any noncommercial use, distribution, and reproduction in any medium, provided you give appropriate credit to the original author(s) and the source, provide a link to the Creative Commons license, and indicate if changes were made.

\section{References}

1. Russ SA, Larson K, Halfon N. A national profile of childhood epilepsy and seizure disorder. Pediatrics. 2012;129(2):256-64.

2. Ostendorf AP, Ng YT. Treatment-resistant Lennox-Gastaut syndrome: therapeutic trends, challenges and future directions. Neuropsychiatr Dis Treat. 2017;13:1131-40.

3. Glauser T, Ben-Menachem E, Bourgeois B, et al. Updated ILAE evidence review of antiepileptic drug efficacy and effectiveness as initial monotherapy for epileptic seizures and syndromes. Epilepsia. 2013;54(3):551-63.

4. Kwan P, Brodie MJ. Early identification of refractory epilepsy. N Engl J Med. 2000;342(5):314-9.

5. Campbell CT, Phillips MS, Manasco K. Cannabinoids in pediatrics. J Pediatr Pharmacol Ther. 2017;22(3):176-85.

6. Vilela LR, Lima IV, Kunsch EB, et al. Anticonvulsant effect of cannabidiol in the pentylenetetrazole model: pharmacological mechanisms, electroencephalographic profile, and brain cytokine levels. Epilepsy Behav. 2017;75:29-35.

7. Thomas A, Baillie GL, Phillips AM, Razdan RK, Ross RA, Pertwee RG. Cannabidiol displays unexpectedly high potency as an antagonist of $\mathrm{CB} 1$ and $\mathrm{CB} 2$ receptor agonists in vitro. Br J Pharmacol. 2007;150(5):613-23.

8. Ross HR, Napier I, Connor M. Inhibition of recombinant human T-type calcium channels by delta9-tetrahydrocannabinol and cannabidiol. J Biol Chem. 2008;283(23):16124-34.

9. Ghovanloo MR, Shuart NG, Mezeyova J, Dean RA, Ruben PC, Goodchild SJ. Inhibitory effects of cannabidiol on voltage-dependent sodium currents. J Biol Chem. 2018;293(43):16546-58.

10. Bisogno T, Hanus L, De Petrocellis L, et al. Molecular targets for cannabidiol and its synthetic analogues: effect on vanilloid VR1 receptors and on the cellular uptake and enzymatic hydrolysis of anandamide. Br J Pharmacol. 2001;134(4):845-52.

11. Gaston TE, Szaflarski JP. Cannabis for the treatment of epilepsy: an update. Curr Neurol Neurosci Rep. 2018;18(11):73.

12. Devinsky O, Cilio MR, Cross H, et al. Cannabidiol: pharmacology and potential therapeutic role in epilepsy and other neuropsychiatric disorders. Epilepsia. 2014;55(6):791-802.

13. Wong SS, Wilens TE. Medical cannabinoids in children and adolescents: a systematic review. Pediatrics. 2017;140(5):1-18.

14. Devinsky O, Marsh E, Friedman D, et al. Cannabidiol in patients with treatment-resistant epilepsy: an open-label interventional trial. Lancet Neurol. 2016;15(3):270-8.

15. Devinsky O, Cross JH, Laux L, et al. Trial of cannabidiol for drug-resistant seizures in the Dravet syndrome. N Engl J Med. 2017;376(21):2011-20.

16. Tzadok M, Uliel-Siboni S, Linder I, et al. CBD-enriched medical cannabis for intractable pediatric epilepsy: the current Israeli experience. Seizure. 2016;35:41-4. 
17. Devinsky O, Patel AD, Cross JH, et al. Effect of cannabidiol on drop seizures in the Lennox-Gastaut syndrome. N Engl J Med. 2018;378(20):1888-97.

18. Devinsky O, Verducci C, Thiele EA, et al. Open-label use of highly purified CBD (Epidiolex ${ }^{\circledR}$ ) in patients with CDKL5 deficiency disorder and Aicardi, Dup15q, and Doose syndromes. Epilepsy Behav. 2018;86:131-7.

19. Thiele EA, Marsh ED, French JA, et al. Cannabidiol in patients with seizures associated with Lennox-Gastaut syndrome (GWPCARE4): a randomised, double-blind, placebo-controlled phase 3 trial. Lancet. 2018;391(10125):1085-96.

20. US Food and Drug Administration. FDA approves first drug comprised of an active ingredient derived from marijuana to treat rare, severe forms of epilepsy. 2018. https://www.fda.gov/newsevents/ newsroom/pressannouncements/ucm611046.htm. Accessed 2 Jan 2018.

21. Devinsky O, Patel AD, Thiele EA, et al. Randomized, dose-ranging safety trial of cannabidiol in Dravet syndrome. Neurology. 2018;90(14):e1204-11.

22. Szaflarski JP, Bebin EM, Comi AM, et al. Long-term safety and treatment effects of cannabidiol in children and adults with treatment-resistant epilepsies: expanded access program results. Epilepsia. 2018;59(8):1540-8.
23. Yamaori S, Ebisawa J, Okushima Y, Yamamoto I, Watanabe K. Potent inhibition of human cytochrome P450 3A isoforms by cannabidiol: role of phenolic hydroxyl groups in the resorcinol moiety. Life Sci. 2011;88(15-16):730-6.

24. Jiang R, Yamaori S, Okamoto Y, Yamamoto I, Watanabe K. Cannabidiol is a potent inhibitor of the catalytic activity of cytochrome P450 2C19. Drug Metab Pharmacokinet. 2013;28(4):332-8.

25. Bergamaschi MM, Queiroz RH, Zuardi AW, Crippa JA. Safety and side effects of cannabidiol, a Cannabis sativa constituent. Curr Drug Saf. 2011;6(4):237-49.

26. Geffrey AL, Pollack SF, Bruno PL, Thiele EA. Drug-drug interaction between clobazam and cannabidiol in children with refractory epilepsy. Epilepsia. 2015;56(8):1246-51.

27. Taylor L, Gidal B, Blakey G, Tayo B, Morrison G. A phase I, randomized, double-blind, placebo-controlled, single ascending dose, multiple dose, and food effect trial of the safety, tolerability and pharmacokinetics of highly purified cannabidiol in healthy subjects. CNS Drugs. 2018;32(11):1053-67.

28. Sands TT, Rahdari S, Oldham MS, Caminha Nunes E, Tilton N, Cilio MR. Long-term safety, tolerability, and efficacy of cannabidiol in children with refractory epilepsy: results from an expanded access program in the US. CNS Drugs. 2018;33(1):47-60.

\section{Affiliations}

\section{James W. Wheless ${ }^{1}$ - Dennis Dlugos ${ }^{2} \cdot$ Ian Miller ${ }^{3}$. D. Alexander $\mathrm{Oh}^{4,11} \cdot$ Neha Parikh $^{4}$. Steven Phillips ${ }^{5}$. J. Ben Renfroe ${ }^{6}$. Colin M. Roberts $^{7}$. Isra Saeed ${ }^{8}$. Steven P. Sparagana ${ }^{9} \cdot \operatorname{Jin} \mathrm{Yu}^{4} \cdot$ Maria Roberta Cilio $^{8,10}$ on behalf of the INS011-14-029 Study Investigators}

1 University of Tennessee Health Science Center, Le Bonheur Children's Hospital, Memphis, TN, USA

2 Children's Hospital of Philadelphia, Perelman School of Medicine at the University of Pennsylvania, Philadelphia, PA, USA

3 Nicklaus Children's Hospital, Miami, FL, USA

4 INSYS Development Company, Inc., Chandler, AZ, USA

5 Mary Bridge Children's Neurology Clinic, Tacoma, WA, USA

6 Child Neurology Center of Northwest Florida, Gulf Breeze, FL, USA
7 Doernbecher Childhood Epilepsy Program, Department of Pediatrics, Oregon Health and Science University, Portland, OR, USA

8 UCSF Benioff Children's Hospital, University of California San Francisco, San Francisco, CA, USA

9 Texas Scottish Rite Hospital for Children, Dallas, TX, USA

10 Saint-Luc University Hospital, University of Louvain, Brussels, Belgium

11 Present Address: Arena Pharmaceuticals, San Diego, CA, USA 